\title{
Relationship between physical characteristics and physiological responses during maximal arm cranking in paraplegics
}

\author{
M Yamasaki ${ }^{1}$, T Komura ${ }^{1}$, Y Tahara ${ }^{2}$, Satoshi Muraki ${ }^{3}, \mathrm{~N}$ Tsunawake ${ }^{3}$, Y Ehara ${ }^{4}$ and K Fujiie \\ ${ }^{1}$ Department of Health Science, Hiroshima University, Hiroshima, Japan; ${ }^{2}$ Department of Health and Physical \\ Education, Nagasaki University, Nagasaki, Japan; ${ }^{3}$ Department of Physical Education, Nagasaki Prefectural \\ Women's Junior College, Nagasaki, Japan; ${ }^{4}$ Department of Medical Engineering, Spinal Injuries Center, Fukuoka, Japan
}

\begin{abstract}
The purpose of this study was to elucidate the main physical factor(s) affecting cardiorespiratory responses during maximal arm cranking exercise in patients with paraplegia. Peak oxygen uptake (peak $\mathrm{VO}_{2}$ ), peak pulmonary ventilation (peak VE) and peak heart rate (peak HR) were measured during maximal arm cranking exercise in 28 Japanese male patients. A cluster analysis was applied to the data for peak $\mathrm{VO}_{2}$, peak $\mathrm{HR}$ and peak $\mathrm{VE}$, and then the subjects were classified into four groups (A, B, C and D). Group A showed high peak VE and peak $\mathrm{HR}$ and low peak $\mathrm{VO}_{2}$, Group $\mathrm{B}$ low peak $\mathrm{VO}_{2}$ and high values for other parameters, Group $\mathrm{C}$ the greatest physiological values for all measurements among the groups and, in contrast, Group D showed low peak $\mathrm{VO}_{2}$ and the lowest peak VE and peak HR among the groups. The subjects in Group $\mathrm{C}$ had low level of spinal cord injury and were sports participants. On the other hand, duration since injury was not related to the cardiorespiratory responses during maximal arm cranking. These findings indicate that the effects on these responses of years since injury are subordinate to those of the level of spinal cord injury and training.
\end{abstract}

Keywords: arm cranking exercise; peak oxygen uptake; wheelchair sport; paraplegics; spinal cord injury

\section{Introduction}

It is well known that the cardiorespiratory responses in able-bodied people during maximal work are dependent on many physical factors including age, sex, and training level. ${ }^{1}$ In addition to these, in patients with paraplegia the level of spinal cord injury (SCI) and years since SCI should be taken into consideration. To study the cardiorespiratory responses during maximal work in these subjects, many investigators have divided them into several groups according to the level of $\mathrm{SCI}^{2-6}$ or physical training, ${ }^{7-10}$ because of the great effect that these factors are considered to have on these responses.

By using such methods in which the subjects are grouped in advance, one can identify the relationship between the cardiorespiratory responses and the level of SCI or physical training. However, these methods may mask the effects of individual differences in other characteristics such as age, body size and years since injury.

One method of examining the effects of physical characteristics on the cardiorespiratory responses

Correspondence: M Yamasaki

Present address: Department of Health Science, Hiroshima University, 1-7-1 Kagamiyama Higashi-Hiroshima, 739, Japan during maximal work is to group the subjects according to their cardiorespiratory responses. By this method, data can be obtained for a group with homogenous response pattern, and by subsequently analyzing the characteristics of each group, the physical factor(s) that influence the cardiorespiratory responses during maximal work can be identified. Such an investigation has apparently not been carried out in patients with paraplegia.

The aim of this study, therefore, was to classify the subjects according to their cardiorespiratory responses during maximal arm cranking and to elucidate the main physical factor(s) affecting these responses. For this purpose, we applied a cluster analysis to the data for oxygen uptake $\left(\mathrm{VO}_{2}\right)$, and pulmonary ventilation (VE) and heart rate (HR) during maximal work. In this study, we focused upon the effects of the number of years since injury, the level of SCI, and physical training.

\section{Materials and methods}

\section{Subjects}

The subjects were 28 Japanese males with paraplegia whose physical characteristics are summarized in Table 
1 in descending order of injury level. The 16 subjects who participated in wheelchair sports, such as basketball, distance running, or tennis, more than three times a week were defined as sports participants. All had paralyzed legs and were wheelchair users due to SCI but were otherwise healthy. Prior to his participation in the study, written informed consent was obtained from each subject.

\section{Testing protocols}

Each subject performed arm cranking exercise on a mechanically braked arm cranking ergometer (Monark Rehab Trainer model 881E) while seated in his immobilized wheelchair. The arm cranking ergometer was operated at the rate of 50 revolutions per minute, beginning at $0-\mathrm{W}$ power output and increasing by $5 \mathrm{~W}$ every minute until the subject could no longer keep pace with the metronome. More tests were terminated after 11-15 min of exercise. Before the experimental testing to obtain physiological variables during maximal arm cranking, each subject was allowed to complete several practice sessions on the arm cranking ergometer to become accustomed to the testing procedure. The room temperature was controlled at within the range from $24-26^{\circ} \mathrm{C}$.

Table 1 Physical characteristics of the subjects

\begin{tabular}{|c|c|c|c|c|c|c|}
\hline Subject & $\begin{array}{c}\text { Age } \\
\text { (years) }\end{array}$ & $\begin{array}{c}\text { Weight } \\
\quad(k g)\end{array}$ & $\begin{array}{c}\text { Height } \\
(\mathrm{cm})\end{array}$ & $\begin{array}{c}\text { Injury } \\
\text { level }\end{array}$ & $\begin{array}{l}\text { Years } \\
\text { since } \\
\text { injury }\end{array}$ & $\begin{array}{c}\text { Sports } \\
\text { partici- } \\
\text { pation }\end{array}$ \\
\hline 1 & 46 & 57.7 & 172 & T3 & 26 & Marathon \\
\hline 2 & 27 & 51.0 & 168 & $\mathrm{~T} 4$ & 7 & \\
\hline 3 & 44 & 48.8 & 172 & $\mathrm{~T} 4,5$ & 16 & Marathon \\
\hline 4 & 29 & 42.2 & 172 & $\mathrm{~T} 5 *$ & 6 & \\
\hline 5 & 32 & 54.5 & 173 & $\mathrm{~T} 5$ & 14 & \\
\hline 6 & 26 & 45.7 & 157 & $\mathrm{~T} 6,7$ & 8 & Basketball \\
\hline 7 & 25 & 54.0 & 170 & $\mathrm{~T} 7$ & 2 & Marathon \\
\hline 8 & 47 & 45.0 & 160 & $\mathrm{~T} 8$ & 20 & \\
\hline 9 & 36 & 67.7 & 173 & T9 & 6 & Marathon \\
\hline 10 & 39 & 62.5 & 165 & $\mathrm{~T} 10^{*}$ & 16 & \\
\hline 11 & 30 & 53.6 & 175 & $\mathrm{~T} 11 *$ & 8 & Tennis \\
\hline 12 & 49 & 58.0 & 170 & $\mathrm{~T} 11$ & 22 & Tennis \\
\hline 13 & 51 & 57.0 & 162 & $\mathrm{~T} 12$ & 25 & Basketball \\
\hline 14 & 52 & 61.0 & 163 & $\mathrm{~T} 12$ & 17 & \\
\hline 15 & 39 & 45.7 & 165 & T12 & 18 & \\
\hline 16 & 42 & 67.0 & 170 & $\mathrm{~T} 12$ & 25 & \\
\hline 17 & 27 & 48.5 & 160 & $\mathrm{~T} 12$ & 3 & Basketball \\
\hline 18 & 35 & 58.0 & 175 & $\mathrm{~T} 12, \mathrm{~L} 1$ & 7 & Tennis \\
\hline 19 & 45 & 58.5 & 173 & $\mathrm{~T} 12, \mathrm{~L} 1 *$ & 25 & Tennis \\
\hline 20 & 44 & 78.8 & 176 & L1 & 20 & \\
\hline 21 & 41 & 77.0 & 183 & L1 & 4 & Basketball \\
\hline 22 & 48 & 67.1 & 158 & $\mathrm{~L} 1 *$ & 13 & \\
\hline 23 & 32 & 46.0 & 164 & L1 & 9 & Marathon \\
\hline 24 & 38 & 62.0 & 166 & $\mathrm{~L} 1,2 *$ & 9 & Tennis \\
\hline 25 & 37 & 56.5 & 174 & L2 & 12 & \\
\hline 26 & 28 & 46.0 & 164 & L2 & 5 & Marathon \\
\hline 27 & 21 & 60.1 & 165 & L3 & 1 & Basketbal \\
\hline 28 & 41 & 51.9 & 158 & L3 & 9 & \\
\hline
\end{tabular}

*incomplete injury
Physiological variables

During each exercise test, $\mathrm{VO}_{2}$ and $\mathrm{VE}$ were measured both with a computerized system and by the Douglas bag method. The computerized system provides on-line measurement using an automated gas and flow analzyer with a computer, Aeromonitor AE-280 (Minato Medical Science Co., Ltd., Japan). In the Douglas bag method, VE was measured with a dry gas meter and the $\mathrm{O}_{2}$ and $\mathrm{CO}_{2}$ concentrations of samples of expired air were analyzed using an electrochemical $\mathrm{O}_{2}$ and $\mathrm{CO}_{2}$ analyzer (Respina 1H26, NEC-Sanei, Japan). $\mathrm{VO}_{2}$ and $\mathrm{VE}$ were recorded at 30-s intervals throughout the exercise. HR was continuously monitored from chest electrodes (modified CM5 placement). The peak $\mathrm{VO}_{2}$, peak $\mathrm{VE}$ and peak $\mathrm{HR}$ were utilized for analysis, with the peak VE and peak HR defined as the VE and $\mathrm{HR}$ at the time of peak $\mathrm{VO}_{2}$, respectively. Peak $\mathrm{VO}_{2}$ was determined as the greatest $\mathrm{VO}_{2}$ during each test.

\section{Statistical analysis}

The cluster analysis by Ward's method was applied to the data for peak $\mathrm{VO}_{2}$, peak $\mathrm{VE}$ and peak $\mathrm{HR}$, transformed into standardized values ( $Z$ scores), to classify the subjects into several groups. The means and standard deviations (SD) of physical characteristics, peak $\mathrm{VO}_{2}$, peak $\mathrm{VE}$ and peak $\mathrm{HR}$ were then calculated for each group. The one-way Kruskal-Wallis analysis of variance (ANOVA) was used for statistical comparison among the groups. When a significant difference was found in the ANOVA, the difference between means was tested with Mann-Whitney test. All $P$ values less than 0.05 were considered significant.

\section{Results}

Figure 1 shows a dendrogram identified by the cluster analysis applied to the data for peak $\mathrm{VO}_{2}$, peak $\mathrm{HR}$ and peak VE in Table 2 as measures of the subjects' physiological response during the maximal arm cranking exercise. As a result, the subjects could be apparently divided into four groups (A, B, C and D).

The peak $\mathrm{VO}_{2}$, peak HR and peak VE in each group are illustrated in Figures 2, 3 and 4, respectively. Because the Kruskal-Wallis ANOVA indicated significant differences among groups for each measurement $(P<0.01)$, the differences between means were compared for all measurements using the MannWhitney test. The test revealed significant differences for peak $\mathrm{VO}_{2}$ between groups $(P<0.05$ or $P<0.01)$. On the other hand, significant differences of peak HR were recognized only between Group D and the other groups $(P<0.01)$. Groups $\mathrm{B}$ and $\mathrm{C}$ showed significantly greater peak VE than Groups A and D $(P<0.01)$.

Table 3 shows the physical characteristics of each group. The ANOVA applied to the data for age, weight, height and years since injury revealed significant differences found only in weight $(P<0.05)$, 


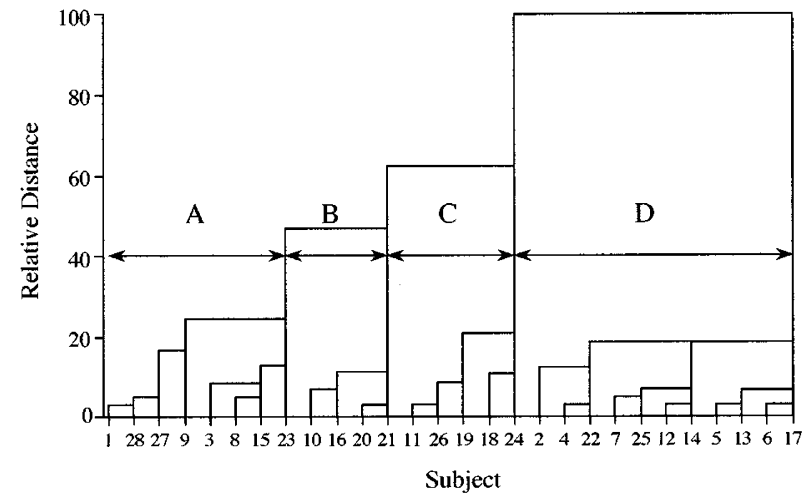

Figure 1 A dendrogram obtained from the cluster analysis applied to the data for peak $\mathrm{VO}_{2}$, peak HR and peak VE. In this Figure, the closer is the relationship between the profiles of the subjects, the shorter is the relative distance between branches. Four clusteres could be obtained; Group A, B, C and D

Table 2 Physiological responses during maximal arm cranking in the subjects

\begin{tabular}{|c|c|c|c|c|}
\hline Subject & $\begin{array}{c}\text { Peak } \mathrm{VO}_{2} \\
\left(\text { l.min }^{-1}\right)\end{array}$ & $\begin{array}{c}\text { Peak } \mathrm{VO}_{2} \\
\left(\begin{array}{l}\text { l.min } \\
\mathrm{kg}^{-1}\end{array}\right)\end{array}$ & $\begin{array}{l}\text { Peak HR } \\
\text { (beats. } \\
\text { min }^{-I)}\end{array}$ & $\begin{array}{c}\text { Peak VE } \\
(B T P S) \\
\left(\text { l.min }^{-1}\right)\end{array}$ \\
\hline 1 & 1.428 & 24.7 & 182 & 61.7 \\
\hline 2 & 1.010 & 19.8 & 144 & 43.5 \\
\hline 3 & 1.470 & 30.1 & 163 & 47.6 \\
\hline 4 & 1.050 & 24.9 & 141 & 53.3 \\
\hline 5 & 1.230 & 22.6 & 161 & 49.2 \\
\hline 6 & 1.150 & 25.2 & 157 & 47.2 \\
\hline 7 & 1.290 & 23.9 & 157 & 60.5 \\
\hline 8 & 1.126 & 25.0 & 166 & 55.4 \\
\hline 9 & 1.742 & 25.7 & 201 & 71.6 \\
\hline 10 & 1.220 & 19.5 & 165 & 81.5 \\
\hline 11 & 1.700 & 31.7 & 187 & 73.6 \\
\hline 12 & 1.235 & 21.3 & 147 & 59.3 \\
\hline 13 & 1.304 & 22.9 & 156 & 52.4 \\
\hline 14 & 1.286 & 21.1 & 152 & 64.9 \\
\hline 15 & 1.240 & 27.1 & 169 & 58.7 \\
\hline 16 & 1.180 & 17.6 & 178 & 75.5 \\
\hline 17 & 1.210 & 24.9 & 156 & 47.1 \\
\hline 18 & 2.110 & 36.4 & 183 & 100.9 \\
\hline 19 & 1.946 & 33.3 & 174 & 75.3 \\
\hline 20 & 1.585 & 20.1 & 184 & 86.2 \\
\hline 21 & 1.724 & 22.4 & 182 & 85.0 \\
\hline 22 & 1.680 & 25.0 & 136 & 57.5 \\
\hline 23 & 1.300 & 28.3 & 155 & 71.7 \\
\hline 24 & 1.909 & 30.8 & 168 & 98.9 \\
\hline 25 & 1.190 & 21.1 & 160 & 65.6 \\
\hline 26 & 1.421 & 30.9 & 187 & 78.0 \\
\hline 27 & 1.400 & 23.3 & 174 & 56.6 \\
\hline 28 & 1.270 & 24.5 & 178 & 60.8 \\
\hline
\end{tabular}

with the mean weight being significantly greater in Group B than in the other groups $(P<0.05)$. Groups $\mathrm{A}$ and $\mathrm{D}$ included subjects with lesions from the high thoracic level to the lumbar region. In contrast, there

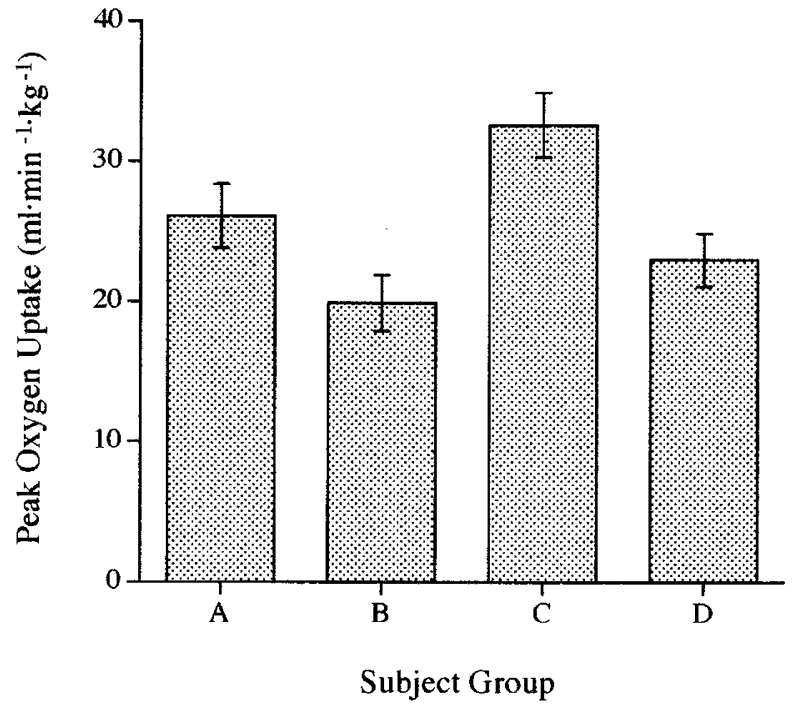

Figure 2 Peak $\mathrm{VO}_{2}$ in each group. Significant differences were found between the groups $(P<0.05)$

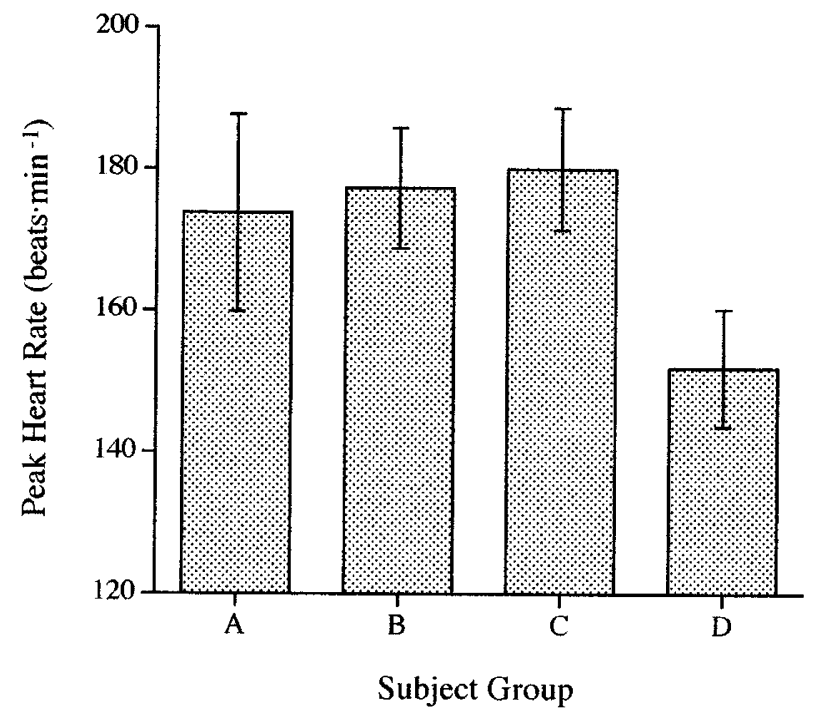

Figure 3 Peak HR in each group. Significant differences were found between Group D and other groups $(P<0.01)$

were none with a high thoracic lesion level in Group B or C. The proportion of sports participants was five of eight $(63 \%)$ in Group A, one of four $(25 \%)$ in Group B, all five (100\%) in Group C, and five of $11(45 \%)$ in Group D. Subjects with incomplete lesion were included in all groups.

\section{Discussion}

In the present study, by applying a cluster analysis to the data for peak $\mathrm{VO}_{2}$, peak $\mathrm{VE}$ and peak $\mathrm{HR}$, we classified the subjects into four groups. Group A 


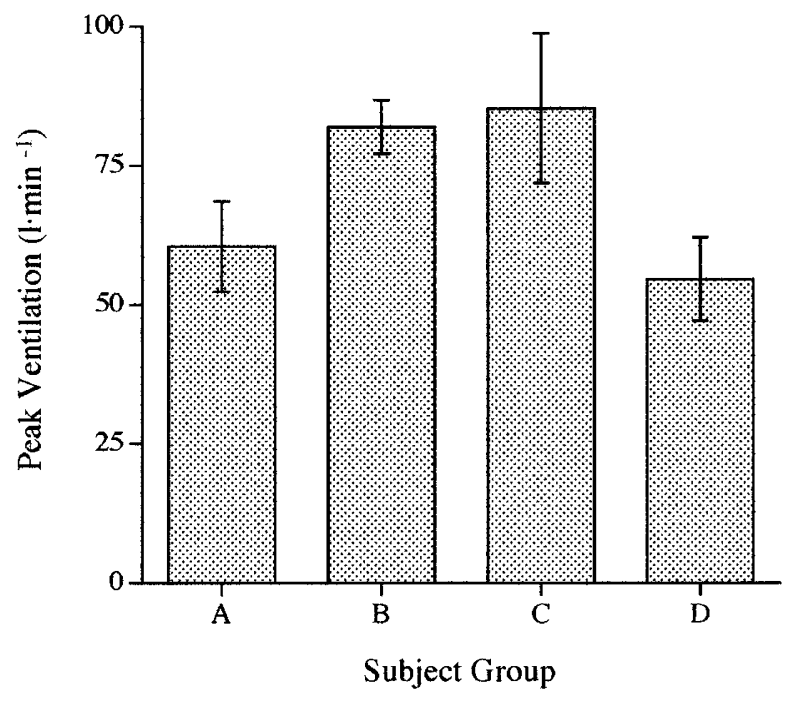

Figure 4 Peak VE in each group. The HR values in Groups $\mathrm{B}$ and $\mathrm{C}$ were significantly greater than those in Groups A and D $(P<0.01)$

Table 3 Physical characteristics of each subject group

\begin{tabular}{lccrcr}
\hline $\begin{array}{l}\text { Group } \\
(N)\end{array}$ & $\begin{array}{c}\text { Age } \\
\text { (year) }\end{array}$ & $\begin{array}{c}\text { Weight } \\
\text { (kg) }\end{array}$ & $\begin{array}{c}\text { Height } \\
(\mathrm{cm})\end{array}$ & $\begin{array}{c}\text { Injury } \\
\text { level }\end{array}$ & $\begin{array}{c}\text { Years } \\
\text { since } \\
\text { injury }\end{array}$ \\
\hline A & 38.3 & 52.9 & 166.1 & T3-L3 & 13.1 \\
$(8)$ & 8.6 & 8.2 & 5.6 & & 8.3 \\
B & 41.5 & 71.3 & 173.5 & T10-L1 & 16.3 \\
$(4)$ & 2.1 & 7.8 & 7.8 & & 9.0 \\
C & 35.2 & 55.6 & 170.6 & T11-L2 & 10.8 \\
$(5)$ & 6.8 & 6.1 & 5.2 & & 8.1 \\
D & 36.6 & 54.1 & 166.1 & T4-L2 & 11.7 \\
$(11)$ & 11.1 & 7.1 & 6.2 & & 7.5 \\
\hline
\end{tabular}

Group B showed significantly greater weight than the other groups $(P<0.05)$

showed high peak $\mathrm{VE}$ and peak $\mathrm{HR}$ and low peak $\mathrm{VO}_{2}$, Group B low peaks $\mathrm{VO}_{2}$ and high peak VE and peak $\mathrm{HR}$, Group $\mathrm{C}$ the greatest values among the groups for all of peak $\mathrm{VO}_{2}$, peak $\mathrm{VE}$ and peak HR. In contrast to Group C, Group D showed low peak $\mathrm{VO}_{2}$ and the lowest peak VE and peak HR among the groups. Thus, the subjects could be grouped according to their cardiorespiratory responses during the maximal arm cranking exercise. Cluster analysis seems a useful method of identifying the subject groups with distinctive characteristics.

It is well established that physically trained subjects show higher peak $\mathrm{VO}_{2}$ and peak $\mathrm{HR}$ than their physically untrained counterparts. It has also been demonstrated that the peak $\mathrm{VO}_{2}$ is related to the level of SCI. Hooker and Wells ${ }^{11}$ reviewed the peak physiological responses recorded in trained paraplegic athletes in their studies conducted since 1986 and indicated that physical training involving wheelchair propulsion can markedly enhance upper body cardiorespiratory fitness. In the present study, the subjects in Group $\mathrm{C}$, who showed the greatest peak $\mathrm{VO}_{2}$ and peak $\mathrm{HR}$, were all sports participants, and their level of SCI was relatively low (below T11). The peak $\mathrm{VO}_{2}$ and peak HR in this group are comparable to those reported for physically well-trained subjects with paraplegia with a low level of SCI. ${ }^{5,12}$ On the other hand, the subjects in Group D, even though five of them were sports participants, showed low values for all physiological measurements, and their peak HR and peak VE were the lowest among the groups. The proportion of the subjects with high lesion (above Th7) was the highest (about $45 \%$ ) in this group. Thus, one might expect that the low physiological values were attributable to the high level of the lesion in these subjects.

We found that the cardiorespiratory responses during maximal work in these subjects were independent of their age or the number of years since the injury. It is established that peak $\mathrm{VO}_{2}$ decreases gradually with aging in able-bodied persons. ${ }^{13-15}$ In addition, Sawka et al $^{16}$ found that peak $\mathrm{VO}_{2}$ decreased linearly with advancing age in 18 wheelchair-dependent subjects including five patients with paraplegia. In the present study, we failed to find a significant effect of age on maximal respiratory responses in spite of the wide range of the subjects' ages (from 21 to 52 years). It may be that age has less effect than does either the level of SCI or physical training; otherwise the sample size might be too small to demonstrate the effect of age. One unexpected finding of the present investigation is that there were significant differences in weight between Group B and the other groups. Although the subjects in this group showed high peak HR and peak $\mathrm{VE}$, the peak $\mathrm{VO}_{2}$ expressed as a function of body weight was relatively low.

In conclusion, the present findings indicate that these subjects could be grouped according to their cardiorespiratory responses during the maximal arm cranking exercise. The group that showed the highest peak $\mathrm{VO}_{2}$ was recognized as showing low level of SCI and high level of physical activity. On the other hand, durations since the SCI was not related to the cardiorespiratory responses during maximal arm cranking. In patients with paraplegia, the effect of duration since the injury on these responses seems to be subordinate to those of the level of SCI and physical training.

\section{References}

1 Åstrand PO, Rodahl K. Text Book of Work Physiology. 1986; McGraw-Hill, New York.

2 Burkett LN, Chisum J, Stone W, Fernhall B. Exercise capacity of untrained spinal cord injured individuals and the relationship of peak oxygen uptake to level of injury. Paraplegia 1990; 28: 512 521. 
3 Coutts KD, Rhodes EC, McKenzie DC. Maximal exercise responses of tetraplegics and paraplegics. $J$ Appl Physiol: Respirat Environ Exercise Physiol 1983; 55: 479-482.

4 Veeger HEJ, et al. Peak oxygen uptake and maximal power output of Olympic wheelchair-dependent athletes. Med Sci Sports Exerc 1991; 23: $1201-1209$.

5 Flandrois R, et al. Aerobic performance capacity in paraplegic subjects. Eur J Appl Physiol 1986; 55: 604-609.

6 Yamasaki M, et al. Peak oxygen uptake and respiratory function in persons with spinal cord injury. Appl Human Sci 1996; 15: $13-$ 17.

7 Wicks JR, Oldridge NB, Camerson BJ, Jones NL. Arm cranking and wheelchair ergometry in elite spinal cord athletes. $\mathrm{Med} \mathrm{Sci}$ Sports Exerc 1983; 23: 264-272.

8 Okuma H, Ogata H, Hatada K. Transition of physical fitness in wheelchair marathon competitors over several years. Paraplegia 1989; 27: $237-243$

9 Gass GC, Camp EM. Physiological characteristics of trained Australian paraplegic and tetraplegic subjects. Med Sci Sports 1979; 11: $256-259$.

10 Nilsson S, Staff DH, Pruett EDR. Physical work capacity and the effect of training on subjects with long standing paraplegia. Scand J Rehabil Med 1975; 7: 51 - 56.
11 Hooker SP, Wells CL. Aerobic power of competitive paraplegic road racers. Paraplegia 1992; 30: $428-436$.

12 Eriksson P, Lofstrom L, Ekblom B. Aerobic power during maximal exercise in untrained and well-trained persons with quadriplegia and paraplegia. Scand J Rehabil Med 1988; 20: $141-147$.

13 Åstrand I, Åstrand PO, Hallbäck, Kilbom A. Reduction in maximal oxygen uptake with age. J Appl Physiol 1973; 35: 649654.

14 Dehn MM, Bruce RA. Longitudinal variations in maximal oxygen intake with age and activity. J Appl Physiol 1972; 33: $805-807$.

15 Shephard RJ, Sidney KH. Exercise and aging. In Hutton RS, Philadelphia, PA (eds). Exercise and Sport Sciences Reviews, The Franklin Institute 1989; vol 6: pp. 1-57.

16 Sawka MN et al. Wheelchair exercise performance of the young, middle-aged, and elderly. $J$ Appl Physiol: Respirat Environ Exercise Physiol 1981; 50: $824-828$. 